\title{
Combining In-class Design Problems and EFFECTs to Stimulate Critical Thinking Skills
}

Dr. Nathan Huynh, University of South Carolina

Dr. Juan M Caicedo, University of South Carolina

Dr. Caicedo is currently an associate professor at the Department of Civil and Environmental Engineering at the University of South Carolina. He obtained his doctorate degree from Washington University in St. Louis in 2003. Dr. Caicedo's research interests include engineering education, numerical and experimental research in the areas of structural dynamics, model updating, structural health monitoring, earthquake engineering and structural control. Dr. Caicedo is member of the American Society of Civil Engineers, the George E. Brown Jr. Network for Earthquake Engineering Simulation, the Society of Experimental Mechanics and the American Society of Engineering Educators.

Dr. Charles E. Pierce, University of South Carolina

Jason W Gantt, University of South Carolina 


\title{
Combining In-Class Design Problems and EFFECTs to Stimulate Critical Thinking Skills
}

\begin{abstract}
In this study, we explore how to use the In-Class Design Problems (ICDP) to not only help students learn the class material, but also improve their critical thinking skills. To accomplish this, we use some key elements from the Environments for Fostering Effective Critical Thinking (EFFECTs) pedagogy to get students to guesstimate an answer to a design problem and to reflect on how the learned material helped them answer the design problem. In order to facilitate core knowledge and critical thinking, a necessary and preliminary task is for the instructor to identify students' misconceptions about a topic and use that information to guide students to the proper solution. To this end, this paper proposes a novel approach for identifying students' misconceptions, using word cloud and Bayes theorem. Preliminary results using one of the developed ICDPs for an undergraduate Transportation Engineering course indicate that this is a promising approach.
\end{abstract}

\section{Introduction}

Engineering judgment is generally regarded as a critical attribute of successful engineers. It is generally developed through experience. Engineering judgment goes beyond the development of a solution. It is a product of critical thinking regarding the appropriateness of the solution. However, engineering judgment is not a tangible concept with clearly defined components or procedures that can be easily taught.

Currently, most engineering courses provide students with core knowledge and technical skills. Specifically, engineering students are generally instructed about the procedures for solving problems. To this end, students tend to learn and memorize the procedures, without critically thinking about the procedures themselves and final solutions. For this reason, engineering instructors often strive to not only provide fundamental knowledge in a course but also good engineering judgment ${ }^{1}$.

This study modifies the Environments for Fostering Effective Critical Thinking (EFFECT) instructional approach to improve students' critical thinking skills and engineering judgment. The EFFECT instructional approach is an active learning framework that is problem-based, collaborative, and includes active learning components that are designed to facilitate critical thinking in students ${ }^{2}$. Each EFFECT is centered on a driving question that is designed to elicit critical thinking skills and enhance the transfer of core knowledge through active learning. An outline of the EFFECT components is provided in Figure 1. 


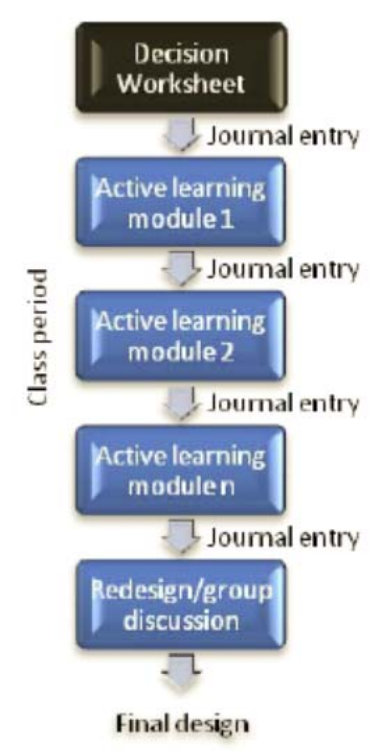

Figure 1. EFFECTs pedagocial structure.

As shown in Figure 1, each EFFECT begins with a decision worksheet. The decision worksheet provides a brief context about the problem and asks students to provide an answer to a design problem. For example, the context to a problem concerning the design of a solar power system ${ }^{3}$ could be as follows. A complete decision worksheet is provided in Appendix 1; it is one of many that have been developed as part of the NSF CCLI project and is publicly accessible.

"A highway rest-stop between Battle Mountain, NV and Winnemucca, NV is being upgraded to include restroom facilities and vending machines. Because of its remote location, electricity is not available from 'the grid', and solar power is being explored as an alternative. "

The question that the students may be asked to answer is:

"How much will it cost to install a solar power system at the renovated rest-stop?"

The decision worksheet typically also includes a few supporting questions designed to help students visualize the problem, think about the data they would need to collect, methods and experiments they would need to conduct in order to answer the driving question. For the solar power EFFECT, the support questions could be:

- Draw a sketch depicting the system as it operates at the highway rest stop. Label the system components.

- List the factors that will determine the size of system components

- What information would you need to gather in order to provide a reasonably good estimate of the cost of the system?

- How could you gather this information?

- Identify some things that your partner thought of that you initially did not, and briefly explain why they are important. 
After completing an individual decision worksheet, students discuss their answers in small groups and then with the entire class. In subsequent class periods, there are demonstrations and hands-on exercises, followed by journal questions that are designed to bridge knowledge gaps to help students answer the driving question. For the solar power EFFECT, the hands-on exercises could involve:

- Developing an estimate of the electric demands of the system

- Calculating the efficiency of an inverter at varying fan speeds and heat settings

- Estimating the necessary battery weight and capacity for the determined demand

- Identifying factors that influence electrical demands of the solar panel, data sources that are used to calculate the solar panel surface, and the solar panel area required to collect a specific kilowatt per day.

The EFFECT culminates in a final student design report that utilizes all of the experimential learning, core knowledge, and engineering judgment that have been cultivated during the EFFECT process. The final design could ask students to: (1) estimate demand, (2) select an inverter based on demand estimation, (3) identify batteries needed, and (4) determine total surface area of Solar Panels needed. A complete final design requirement for this EFFECT is provided in Appendix 2.

As illustrated in Figure 2, the outcome of the application of the EFFECT is that students have received core knowledge, which leads to the development of fundamental technical skills that can be applied to solve design problems. Through this process students develop good "Engineering Judgment" - the capacity to apply critical thinking to assess the rationality, practicality, reasonableness, and correctness of possible solutions to problems ${ }^{3}$. In this way, the EFFECTs pedagogy provides a method for instructors to effectively teach both core knowledge and critical thinking skills.

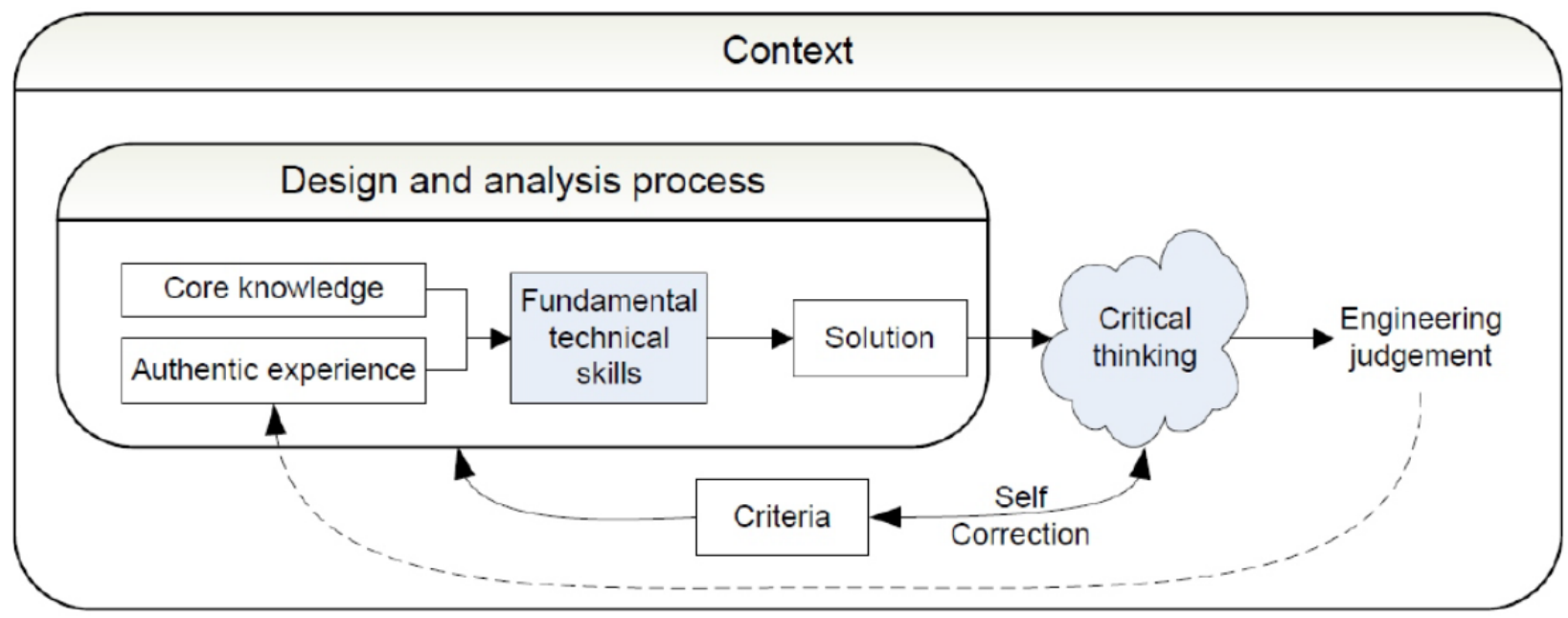

Figure 2. Relationship between design and analysis process, critical thinking, and engineering judgement. 
In this study, we explore how to effectively use the In-Class Design Problems (ICDP) that is to be done by students at the end of each major topic (i.e. chapters). Specifically, we would like to use the ICDPs to not only help students learn the class material, but also improve their critical thinking skills. To accomplish this, we use some key elements from the EFFECTs pedagogy to get students to think and guesstimate an answer to a design problem and to reflect on how the learned material helped them answer the design problem. The study is carried out in an undergraduate Transportation Engineering course with 57 students. The remainder of this paper discusses our modified EFFECT approach and a novel approach for assessing students' learning. Preliminary results are presented and discussed.

\section{Modified EFFECT Approach}

The specific structure of the modified EFFECT approach is as follows. During the first lecture of each of the seven topics, the instructor provides students with a simplified EFFECT decision worksheet that simply asks students to make an educated guess of the answer to a design problem and to list the parameters they considered in estimating their answers. For example, one of the driving questions is "estimate the theoretical stopping distance of a Honda civic with and without antilock brakes from $60 \mathrm{mi} / \mathrm{hr}$ on good, dry, level pavement." The purpose of the decision worksheet is to pique the students' interest and to let them know what it is they will be learning to solve in the next few classes. The students are given time to answer the question on their own and then additional time to discuss the answer with classmates, in groups of 4 to 5 students. Each student records his/her answer as well as the group's answer. This is followed by lectures and homework in a series of subsequent classes. In the homework, students are asked how the topics covered in class and which homework problems can help them answer the driving question. The purpose of this requirement is to make students reflect on the learned material and to remind them of the big picture (i.e. the design problem). Finally, students are given an ICDP which has the same design problem as the one presented in the decision worksheet. In solving the ICDP, students discuss the problem among themselves within the group of 4 to 5 students and across groups. While they do this, the instructor provides assistance as needed. At the end of the ICDP, students are asked to state how their final answers have changed from their initial estimates and explain why. This is done to engage students in metacognition (i.e. assess their own learning). Of particular interest to the instructor is the students' awareness of their own level of knowledge and thought process.

The differences between the EFFECT approach used in this study and a typical EFFECT like the solar power EFFECT discussed previously are: (1) decision worksheets do not include as many supporting questions; (2) there is only one journal entry as opposed to several; (3) there are no hands-on learning modules, just lectures with example problems; and (4) there is no final design problem and report, the ICDP is used instead. This modified EFFECT approach takes fewer classes (from decision worksheet to ICDP) and thus can be used in a transportation engineering class that typically covers about seven topics.

Appendix 3 provides a summary of the topics and decision worksheets developed for an undergraduate Transportation Engineering course with 57 students. They can also be found online at: http://sdii.ce.sc.edu/effects. These driving questions were developed based on the 
teaching material that accompanied the Mannering and Washburn textbook: Highway Engineering and Traffic Analysis ${ }^{4}$.

\section{Analysis of Decision Worksheet Response}

In the developed decision worksheets, students were asked to not only estimate the solution but also provide a list of parameters they considered in their estimation. By analyzing the students' lists of factors, the instructor can identify misconceptions and incorrect use of engineering terminologies. Equipped with this information, the instructor has the opportunity to use it in a way that effectively guides the students to the proper solution approach. The ability to quickly identify students' misconceptions is thus an important step in the process of facilitating core knowledge and critical thinking. In this paper, we propose the use of word clouds to help instructors quickly visualize the student responses. Furthermore, we propose the use of Bayes inference to estimate the probability that certain words would be included in the response.

The frequency of keywords that the students specified for a particular answer provides only partial evidence of their understanding. That is, some students may not understand the design problem fully, but know of terminologies used in a similar context. On the other hand, some students may understand the design problem, but used the wrong terminologies. To identify students' misconceptions, Bayes inference could be used by considering both the students' keywords and the instructor's expectation of the keywords. We surmise that the word cloud showing the posterior probability density function (after including the instructor's expectation of the student knowledge) is a better method than the word cloud showing word frequency in identifying students' misconceptions. Formally, the probability of randomly selecting a particular word is:

$$
P(\text { word } \mid \text { student responses })=k^{-1} P(\text { word }) P(\text { student response } \mid \text { word })
$$

Where $P$ (word) is the prior Probability Density Function (PDF) and it indicates the belief of the instructor on the probability of a particular word. This probability is based on previous interaction between the instructor and the students. P(student responses $\mid$ word) is the likelihood, $P$ (word |student responses) is the posterior probability that combines the information provided by the instructor and the student responses. The parameter $k$ is a normalization constant ${ }^{5}$.

\section{Preliminary Results}

Figure 3 shows the word cloud of the student responses to the driving question, "Suppose we want to construct a road with the following characteristics and that the speed limit on this road is $70 \mathrm{mi} / \mathrm{hr}$. What would be an appropriate radius to allow vehicles to travel on it safely?" Additional information about the driving question can be found in the Appendix. The word cloud was created using http://www.wordle.com. The more times a word is used, the bigger it appears in the word cloud. Thus, the words "Elevation" and "Speed" were the two most used words in the student responses. As expected, other engineering key terminologies such as superelevation, grade and SSD (stopping sight distance) were used less often. 


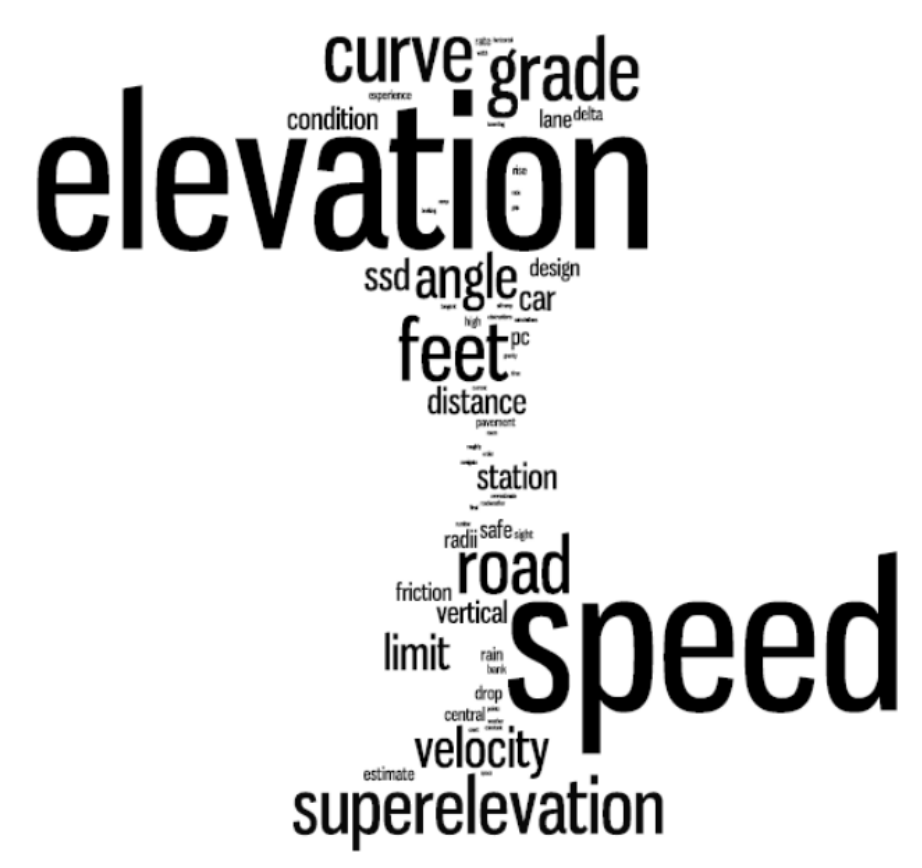

Figure 3. Word cloud of student response from decision worksheet.

Figure 4 shows the word cloud of the posterior probability obtained using Bayes inference. It can be seen that the word "speed" gained importance (bigger) while the word "elevation" became less important (smaller) with respect to the instructor's prior probability. Figure 4 better captures how well the students understand the topic within the context of the EFFECT. It can be used to identify misconceptions from students. For example, it can be inferred that the word "elevation" is misunderstood or misused in this particular context because it is prominent (bigger) in the word cloud in Figure 3, but not Figure 4. That is because this parameter is not expected to play a key role in the solution. Conversely, "friction" is less prominent (smaller) in Figure 3, but is more prominent in Figure 4, which suggests that this term is not understood by students and that the instructor should subsequently explain how friction plays a key role in the solution. 


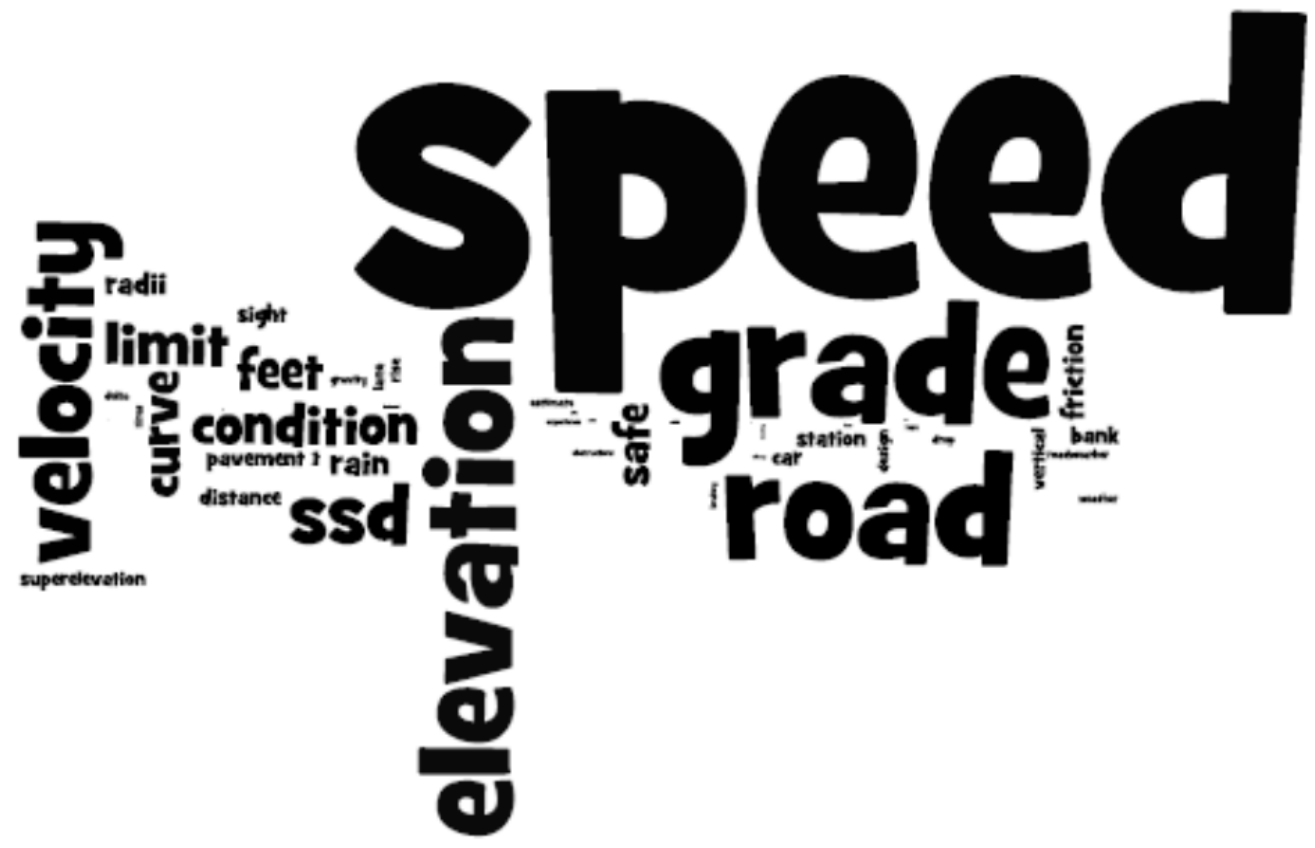

Figure 4. Word cloud of the posterior probability of each word.

\section{Summary and Conclusion}

This study investigates the effectiveness of using ICDPs that are combined with key elements from the EFFECT pedagogical approach to stimulate and improve critical thinking skills of civil engineering students. In order to facilitate core knowledge and critical thinking, a necessary and preliminary task is for the instructor to identify students' misconceptions about a topic and use that information to guide students to the proper solution. To this end, this paper proposes a novel approach for identifying students' misconceptions, using word cloud and Bayes inference. Preliminary results using one of the developed ICDPs indicate that this is a promising approach.

\section{Acknowledgment}

This work is supported by the National Science Foundation under Grant No. 1022971.

\section{Bibliography}

1. Van Mier, J. G. M., \& van Vliet, M. R. A. (1999). Experimentation, numerical simulation and the role of engineering judgement in the fracture mechanics of concrete and concrete structures. Construction and Building Materials, 13, 3-14.

2. J. M. Caicedo, J. Flora, C. Pierce, A. Nichols, W. Graf, and B. Timmerman. Introducing the environments for fostering effective critical thinking (effects). Proceedings of the International Modal Analysis Conference, Orlando, FL, February 4-8, 2008, 2008.

3. I.W. Wait. Solar Power System Design to Promote Critical Thinking in Freshman Engineering Students. Proceedings of the American Society of Engineering Education, San Antonio, TX, June 10-13, 2012. 
4. F.L. Mannering and S.S. Washburn. Principles of Highway Engineering and Traffic Analysis, 5th Edition. John Wiley \& Sons, 2012.

5. A.H-S. Ang and W.H. Tang. Probability Concepts in Engineering Planning and Design, Vol. 1. Wiley, New York, 1975.

\section{Appendix 1: Solar Power EFFECT - Decision Worksheet}

A highway rest-stop between Battle Mountain, NV and Winnemucca, NV is being upgraded to include restroom facilities and vending machines. Because of its remote location, electricity is not available from 'the grid', and solar power is being explored as an alternative.
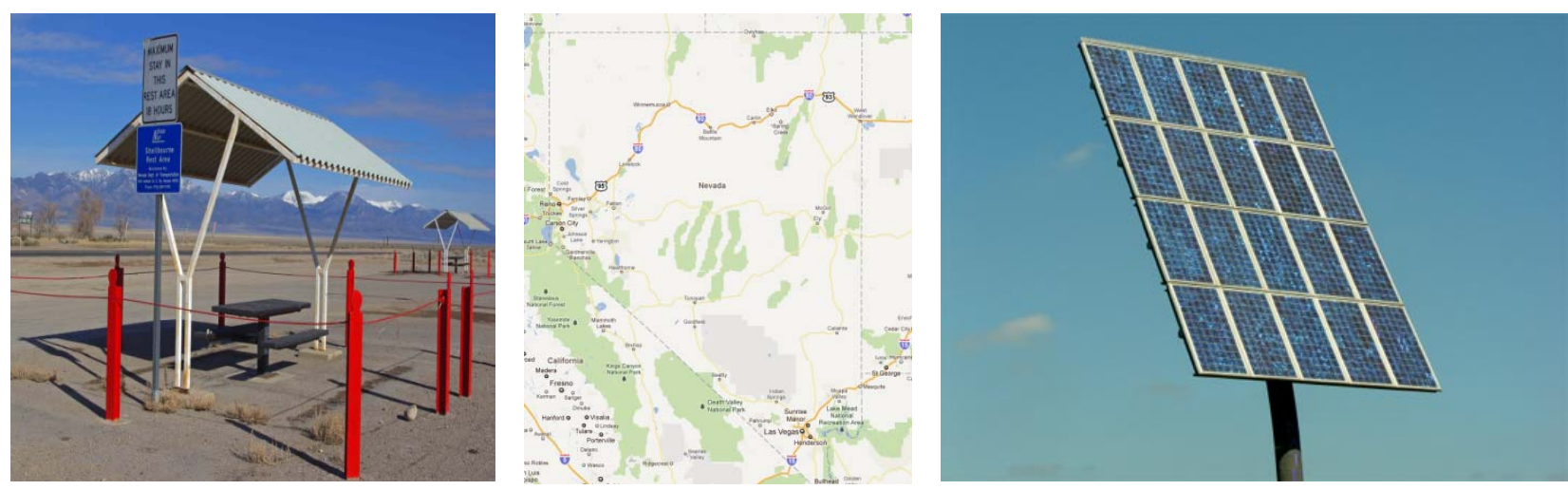

Driving Question: How much will it cost to install a solar power system at the renovated reststop?

\section{Supporting Questions}

- Draw a sketch depicting the system as it operates at the highway rest stop. Label the system components.

- List the factors that will determine the size of system components

- What information would you need to gather in order to provide a reasonably good estimate of the cost of the system?

- How could you gather this information?

- Identify some things that your partner thought of that you initially did not, and briefly explain why they are important. 


\section{Appendix 2: Solar Power EFFECT - Final Design}

Fill in the blanks and submit calculations that address the following sections:

\section{Demand Estimation}

Based on the devices that you believe will be used in the rest stop, revise your Demand Estimation calculations in order to take into account the principles that have been illustrated in the active learning exercises, and the corrections that you previously identified as necessary.

Attach calculations and a summary of your demand estimation, and fill in the blanks below.

Estimated peak electrical requirements for the rest stop:

Estimated power demand for the rest stop: Watts kWh per day

\section{Inverter}

Based on the peak electrical requirements identified above, go to the following website and select an inverter to be used at the rest stop. http://www.solarelectricsupply.com/inverters.html

Fill in the blanks below, attach a printout of the specifications of the inverter that you have selected, and attach a printout of your numerical model of cost (explained below).

Inverter selected - Size / Capacity:

Manufacturer: Model \#:

Efficiency:

Estimate the cost of this inverter by creating a linear-regression model in Excel with the following inverter price data:

\begin{tabular}{ccc} 
Watts & $\begin{array}{c}\text { Cost } \\
(\$)\end{array}$ & Manufacturer \\
\hline 5000 & 4100 & SMA \\
2000 & 1680 & Magnum \\
8000 & 4676 & Radian \\
2000 & 1277 & Exceltech \\
3000 & 1188 & Samlex \\
300 & 241 & Morningstar \\
\hline
\end{tabular}

Estimated Cost of Inverter:

\section{Batteries}

Based on the power demand identified in Part 1, the efficiency of the inverter, the batteries available on this website (http://www.solar-electric.com/batteries.html) and any other factors that you deem important (e.g., extra power storage for cloudy days), fill in the following:

Total battery capacity required (Amp-Hr @ 12 Volts):

Battery manufacturer \& model selected:

Number of Batteries Required:

Total Cost of Batteries: 


\section{Solar Panels}

Based on the estimated power demand for the rest stop (i.e., kWh required per day), the assumption of $15 \%$ efficiency for solar panels, and the solar irradiance data provided below, determine the total surface area of solar panels required for the highway rest stop.

\begin{tabular}{cc} 
Time & $\begin{array}{c}\text { Irradiance } \\
\left(\mathrm{W} / \mathrm{m}^{2}\right)\end{array}$ \\
\hline $7: 00$ & 0.0 \\
$8: 00$ & 14.6 \\
9:00 & 86.1 \\
10:00 & 137.1 \\
$11: 00$ & 182.7 \\
$12: 00$ & 201.1 \\
$13: 00$ & 255.9 \\
14:00 & 293.7 \\
15:00 & 302.7 \\
16:00 & 203.7 \\
17:00 & 0.0 \\
\hline
\end{tabular}

Total surface area of solar panels required $\left(\mathrm{m}^{2}\right)$ :

Assuming \$375 per $\mathrm{m}^{2}$, total cost of solar panels:

Summary: How much will it cost to install a solar power system at this rest stop?

\section{Appendix 3: Transportation EFFECTs - Decision Worksheets}

\section{$\underline{\text { Horizontal Curve }}$}

Suppose we want to construct a road with the following characteristics and that the speed limit on this road is $70 \mathrm{mi} / \mathrm{hr}$. What would be an appropriate radius to allow vehicles to travel on it safely?

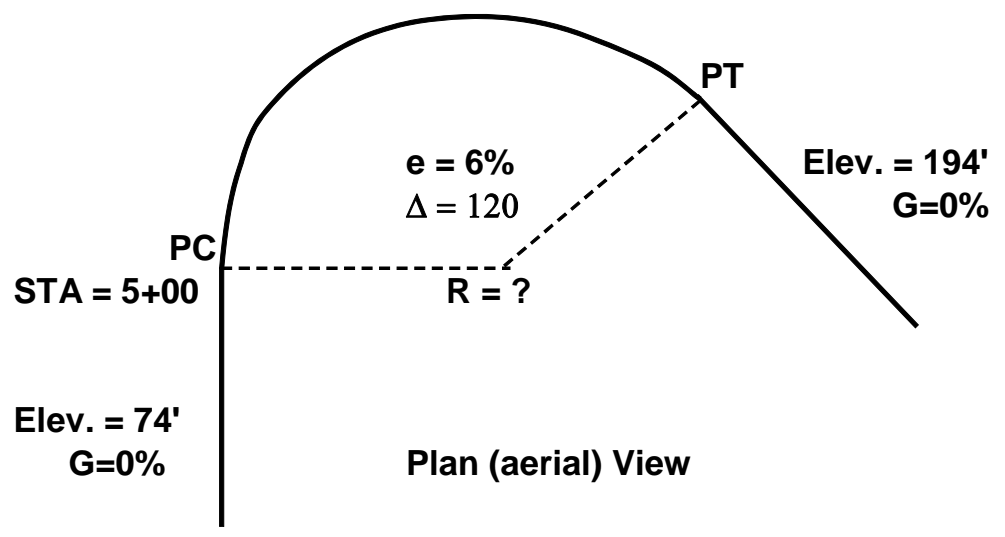

Traffic Flow - Queuing 
The entry plaza to a new sea port is being designed. It is expected that 230 semi-trucks (hauling cargo containers) will arrive during the peak hour of demand. The mean service rate at each entry booth is such that one truck can be processed every 40 seconds.

What is the number of booths that would need to be open to keep the average time waiting in the queue less than 1 minute? Assume that both arrival and departure headways are exponentially distributed.

\section{Level of Service}

A new segment of freeway is being built to connect two existing parallel freeway facilities. The following traffic and roadway characteristics are expected:

\section{Traffic Characteristics}

- $\mathrm{AADT}=86,500 \mathrm{veh} / \mathrm{day}$

- $\mathrm{K}=12 \%$

- $\mathrm{D}=56 \%$

- $\mathrm{PHF}=0.92$

- $6 \%$ trucks and buses

- $2 \% \mathrm{RVs}$

- Primarily commuters

Roadway Characteristics

- Grade in peak direction: 1.5 miles, 2.25 percent

- Total ramp density $=1.25$ per mile

- Lane widths $=12 \mathrm{ft}$

- Shoulder widths $=4 \mathrm{ft}$

How many lanes are necessary to ensure that this new freeway segment will operate at no worse than LOS D during the peak hour in the peak direction?

\section{$\underline{\text { Traffic Signal Design }}$}

Consider the following intersection and characteristics. 


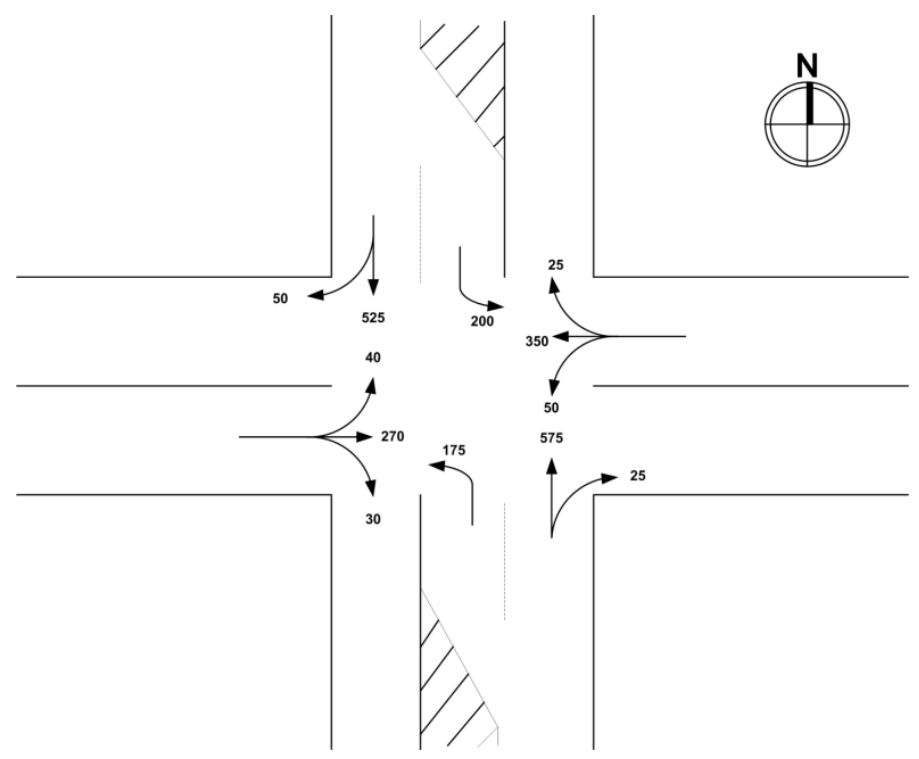

\section{Assume the following:}

- Saturation flow rate per lane $=1800 \mathrm{veh} / \mathrm{h}$ (for protected movements)

- Saturation flow rate per lane $=700 \mathrm{veh} / \mathrm{h}$ (for any lane with permitted movements)

- Start-up lost time/phase: 2 sec; Clearance lost time/phase $=2 \mathrm{sec}$

- Lane widths:

o Thru: $12 \mathrm{ft}$

o Left turn: $11 \mathrm{ft}$

- Speeds:

o $\quad$ E/W: $45 \mathrm{mph}$

o N/S: $35 \mathrm{mph}$

- Vehicle length: $20 \mathrm{ft}$

- Level grade

- Eff. crosswalk width $=8 \mathrm{ft}$

- $\quad \#$ of crossing pedestrians $/$ phase $=15$

What is the cycle length that would minimize the intersection delay?

\section{Traffic Assignment - User Equilibrium}

There are three potential routes from a housing area to the proposed theater site. These routes have the following speed and length characteristics:

\begin{tabular}{|c|c|c|}
\hline Route & Free-Flow Speed (mi/h) & Length (mi) \\
\hline 1 & 45 & 5.5 \\
\hline 2 & 40 & 3.5 \\
\hline 3 & 35 & 3.75 \\
\hline
\end{tabular}

It is known that the individual route travel times increase (in units of minutes) according to the following functions (with $x$ in units of 1000 vehicles per hour): 


\begin{tabular}{|c|c|}
\hline Route & $\begin{array}{c}\text { Travel Time increase, } \\
\text { as a function of traffic volume }\end{array}$ \\
\hline 1 & $0.5 x_{1}$ \\
\hline 2 & $x_{2}$ \\
\hline 3 & $0.25 x_{3}$ \\
\hline
\end{tabular}

If a total of 5500 vehicles go from the origin to destination, estimate how many vehicles will be using Route 1, 2, and 3. 